\title{
Molecular dynamics simulation of the surface tension of aqueous sodium chloride: from dilute to highly supersaturated solutions and molten salt
}

\author{
Xiaoxiang Wang ${ }^{1}$, Chuchu Chen ${ }^{1}$, Kurt Binder ${ }^{2}$, Uwe Kuhn $^{1}$, Ulrich Pöschl ${ }^{1}$, Hang Su ${ }^{3,1}$, and Yafang Cheng ${ }^{1,3}$ \\ ${ }^{1}$ Max Planck Institute for Chemistry, Multiphase Chemistry Department, Hahn-Meitner-Weg 1, 55128 Mainz, Germany \\ ${ }^{2}$ Institut für Physik, Johannes Gutenberg-Universität, Staudinger Weg 7, 55128 Mainz, Germany \\ ${ }^{3}$ Institute for Environmental and Climate Research, Jinan University, 510632 Guangzhou, China
}

Correspondence: Yafang Cheng (yafang.cheng@mpic.de) and Hang Su (h.su@mpic.de)

Received: 30 October 2017 - Discussion started: 8 November 2017

Revised: 29 October 2018 - Accepted: 21 November 2018 - Published: 4 December 2018

\begin{abstract}
Sodium chloride $(\mathrm{NaCl})$ is one of the key components of atmospheric aerosols. The surface tension of aqueous $\mathrm{NaCl}$ solution $\left(\sigma_{\mathrm{NaCl}, \mathrm{sol}}\right)$ and its concentration dependence are essential to determine the equilibrium water vapor pressure of aqueous $\mathrm{NaCl}$ droplets. Supersaturated $\mathrm{NaCl}$ solution droplets are observed in laboratory experiments and under atmospheric conditions, but the experimental data for $\sigma_{\mathrm{NaCl}, \text { sol }}$ are mostly limited up to subsaturated solutions. In this study, the surface tension of aqueous $\mathrm{NaCl}$ is investigated by molecular dynamics (MD) simulations and the pressure tensor method from dilute to highly supersaturated solutions. We show that the linear approximation of concentration dependence of $\sigma_{\mathrm{NaCl} \text {,sol }}$ at molality scale can be extended to the supersaturated $\mathrm{NaCl}$ solution until a molality of $\sim 10.7 \mathrm{~mol} \mathrm{~kg}^{-1}$ (i.e., solute mass fraction $\left(x_{\mathrm{NaCl}}\right)$ of $\sim 0.39$ ). Energetic analyses show that this monotonic increase in surface tension is driven by the increase in excess surface enthalpy $(\Delta H)$ as the solution becomes concentrated. After that, the simulated $\sigma_{\mathrm{NaCl} \text {,sol }}$ remains almost unchanged until $x_{\mathrm{NaCl}}$ of $\sim 0.47$ (near the concentration upon efflorescence). The existence of the "inflection point" at $x_{\mathrm{NaCl}}$ of $\sim 0.39$ and the stable surface tension of $x_{\mathrm{NaCl}}$ between $\sim 0.39$ and $\sim 0.47$ can be attributed to the nearly unchanged excess surface entropy term $(T \cdot \Delta S)$ and the excess surface enthalpy term $(\Delta H)$. After a "second inflection point" at $x_{\mathrm{NaCl}}$ of $\sim 0.47$, the simulated $\sigma_{\mathrm{NaCl} \text {,sol }}$ gradually regains the growing momentum with a tendency to approach the surface tension of molten $\mathrm{NaCl}\left(\sim 175.58 \mathrm{mN} \mathrm{m}^{-1}\right.$ at $298.15 \mathrm{~K}$, MD simulation-based extrapolation). This fast increase in $\sigma_{\mathrm{NaCl}, \mathrm{sol}}$ at $x_{\mathrm{NaCl}}>0.47$ is a process driven by excess surface
\end{abstract}

enthalpy and excess surface entropy. Our results reveal different regimes of concentration dependence of the surface tension of aqueous $\mathrm{NaCl}$ at $298.15 \mathrm{~K}$ : a water-dominated regime $\left(x_{\mathrm{NaCl}}\right.$ from 0 to $\left.\sim 0.39\right)$, a transition regime $\left(x_{\mathrm{NaCl}}\right.$ from $\sim 0.39$ to $\sim 0.47)$ and a molten $\mathrm{NaCl}$-dominated regime $\left(x_{\mathrm{NaCl}}\right.$ from $\sim 0.47$ to 1$)$.

\section{Introduction}

Sodium chloride $(\mathrm{NaCl})$ is one of the most important components of atmospheric aerosol particles (Finlayson-Pitts, 2003; Lewis and Schwartz, 2004). The aqueous $\mathrm{NaCl}$ solution droplet could participate in many atmospheric processes, such as phase transition, cloud activation, ice crystallization, long-range transport and chemical aging (Martin, 2000; Finlayson-Pitts, 2003; Ghorai et al., 2014; Wagner et al., 2015; Chen et al., 2016). To better understand these processes, the concentration-dependent surface tension of aqueous $\mathrm{NaCl}$ solution $\left(\sigma_{\mathrm{NaCl} \text { sol }}\right)$ is essential to determine the equilibrium between $\mathrm{NaCl}$ solution droplet and water vapor (Jarvis and Scheiman, 1968; Dutcher et al., 2010).

Below the saturation point $\left(\sim 6.15 \mathrm{~mol} \mathrm{~kg}^{-1}\right), \sigma_{\mathrm{NaCl} \text {,sol }}$ shows a near-linear dependence on molality (Jarvis and Scheiman, 1968; Johansson and Eriksson, 1974; Aveyard and Saleem, 1976; Weissenborn and Pugh, 1995; Matubayasi et al., 2001) with a slope of $1.73 \pm 0.17$ (Pegram and Record, 2006, 2007). Because of the energy barrier of crystallization during dehydration and size effects at the nanoscale (Martin, 
2000; Biskos et al., 2006; Cheng et al., 2015), supersaturated aqueous $\mathrm{NaCl}$ solution droplets can exist under atmospheric conditions. However, direct measurements of surface tension of supersaturated droplets are challenging due to technical difficulties (Harkins and Brown, 1919; Vargaftik et al., 1983; Richardson and Snyder, 1994; Kumar, 2001). Only recently, Bzdek et al. (2016) overcame these limitations with an optical tweezer method and extended the concentration range to $\sim 8 \mathrm{~mol} \mathrm{~kg}^{-1}$, where the near-linear relationship still holds (Bzdek et al., 2016).

It is a matter of debate to what extent the approximation of a near-linear dependence of surface tension on molality can still be used for $\mathrm{NaCl}$ droplets. Cheng et al. (2015) used the differential Köhler analyses (DKA) method to retrieve the surface tension of $\mathrm{NaCl}$ aqueous droplets, and revealed a large deviation from the near-linear increase at a molality of $\sim 10 \mathrm{~mol} \mathrm{~kg}^{-1}$. In literature, such a deviation in concentrated solution has also been found for other compounds, such as $\mathrm{HNO}_{3}$ (Weissenborn and Pugh, 1996), and it is believed to be typically true for most highly soluble electrolytes (Dutcher et al., 2010). The reason for such deviation remains unclear.

Several models about surface tension have been developed for highly concentrated solutions, e.g., $\mathrm{Li}$ and $\mathrm{Lu}$ (2001), $\mathrm{Li}$ et al. (1999) and Levin and Flores-Mena (2001). Li and Lu (2001) developed a model based on the Gibbs dividing surface concept, where the adsorption and desorption rate constants, saturated surface excess, stoichiometric coefficient of ions and mean ionic activity coefficient are needed. For $\mathrm{NaCl}$ aqueous solutions, this model is suitable for solutions with concentrations up to $\sim 5.5 \mathrm{~mol} \mathrm{~kg}^{-1}$. Li et al. (1999) uses a Debye-Hückel parameter, osmotic coefficient and a proportionality constant from the fitting of measured values to calculate the surface tension, which covers the concentration until the saturation point of bulk $\mathrm{NaCl}$ aqueous solutions. The remaining models are mostly only suitable for the dilute electrolyte solutions, such as the one proposed by Levin and Flores-Mena (2001). In their valid concentration range, these surface tension models produce linear or near-linear concentration dependence of $\sigma_{\mathrm{NaCl} \text {,sol }}$ that agrees well with currently available observations.

One surface tension model that is able to predict $\sigma_{\mathrm{NaCl} \text {,sol }}$ in the whole concentration range from infinitely dilute $\left(x_{\mathrm{NaCl}}=0\right)$ to highly supersaturated solution to molten salts $\left(x_{\mathrm{NaCl}}=1\right)$ was proposed by Dutcher et al. (2010), which has been adopted into the widely used Extended Aerosol Inorganics Model (E-AIM; Wexler and Clegg, 2002). This model is based on the following concept: ions are solvated by the water at low salt concentrations, which means that water molecules form hydration shells around the ions; while at very high salt concentration the water is considered as "solute" that is solvated by the ions, which means that ions form shells around the water molecules (Dutcher et al., 2010). Accordingly, for a diluted solution, the surface tension of water dominates and the surface tension of the solution equals the surface tension of water adjusted by a term that is pro- portional to the solute concentration. For a highly supersaturated solution, a similar relationship can be applied with the surface tension of molten salt as governing element. Legitimately, the model is then constrained by the surface tensions of water and molten salt. The parameterization of this model is obtained by fitting the data of subsaturated solutions. When the aqueous $\mathrm{NaCl}$ solution gets concentrated, this model shows a nonlinear monotonically increasing trend of $\sigma_{\mathrm{NaCl} \text {,sol }}$ generally in good agreement with observations, but no inflection point was introduced. It should be noted that the surface tension as a function of mole fraction of $\mathrm{NaCl}$ according to the Dutcher et al. (2010) model is essentially a linear interpolation between the surface tensions of water and molten $\mathrm{NaCl}$.

In this study, we applied molecular dynamics (MD) simulations and the pressure tensor method to calculate the concentration dependence of $\sigma_{\mathrm{NaCl} \text {,sol }}$ from infinitely dilute $\left(x_{\mathrm{NaCl}}=0\right)$ to highly supersaturated solution to molten salt $\left(x_{\mathrm{NaCl}}=1\right)$. The concentration dependence of $\sigma_{\mathrm{NaCl} \text {,sol }}$ is divided into 3 regimes: a water-dominated regime, a transition regime and a molten $\mathrm{NaCl}$-dominated regime. We compare our results with the Dutcher et al. (2010) model, and present the principal underlying physical chemistry (driving forces) behind the change of surface tension along concentration changes.

\section{Methods}

\subsection{MD simulation}

MD simulations were carried out with the GROMACS 5.1 package (Abraham et al., 2015). The $\mathrm{Na}^{+}$ions, $\mathrm{Cl}^{-}$ions and water molecules were added into a cubic box $(L=5 \mathrm{~nm})$ to imitate the $\mathrm{NaCl}$ solution. The concentrations of simulated solutions are summarized in Table 1. To simulate the surface tension of supersaturated $\mathrm{NaCl}$ aqueous solution, we make use of the time window in the MD simulations before the crystallization starts in the system. The highest $x_{\mathrm{NaCl}}$ we can reach is $\sim 0.64$ (the corresponding concentration is $\sim 30.39 \mathrm{~mol} \mathrm{~kg}^{-1}$ ), below which the simulated surface tensions in three independent runs stably converge after 50 to $100 \mathrm{~ns}$ (Fig. 1). For more concentrated solutions, stable convergence cannot be reached, e.g., large fluctuations are shown in Fig. 1d at $x_{\mathrm{NaCl}}$ of 0.75 .

According to Dutcher et al. (2010), surface tension of liquid or molten $\mathrm{NaCl}$ at $298.15 \mathrm{~K}$ (corresponding $x_{\mathrm{NaCl}}$ is 1 , infinite concentrated solution) can be regarded as the upper boundary of $\sigma_{\mathrm{NaCl} \text {,sol }}$. However, a direct simulation of surface tension of molten $\mathrm{NaCl}$ at $298.15 \mathrm{~K}$ would not be possible, due to excessively large relaxation times of this system at this temperature. It has been found that surface tensions of a very wide range of molten salts can be well described by linear functions of temperature (Sada et al., 1984; Horvath, 1985; Janz, 1988; Dutcher et al., 2010). We thus follow 
Table 1. Concentrations of solution studied in our simulation and the calculated values of surface tension.

\begin{tabular}{|c|c|c|c|c|c|c|c|}
\hline No. & $\begin{array}{r}\text { Number of } \\
\text { water }\end{array}$ & $\begin{array}{l}\text { Number } \\
\text { of } \mathrm{NaCl}\end{array}$ & $\begin{array}{r}\text { Concentration }\left(\mathrm{mol} \mathrm{kg}^{-1}\right) \\
\text { in bulk region }\end{array}$ & $\begin{array}{r}x_{\mathrm{NaCl}} \text { in } \\
\text { bulk region }\end{array}$ & $\begin{array}{r}\text { Concentration }\left(\mathrm{mol} \mathrm{kg}^{-1}\right) \\
\text { of whole solution }\end{array}$ & $\begin{array}{r}x_{\mathrm{NaCl}} \text { of } \\
\text { whole solution }\end{array}$ & $\begin{array}{r}\text { Surface tension } \\
\left(\mathrm{mN} \mathrm{m}^{-1}\right)\end{array}$ \\
\hline 1 & 4142 & 0 & 0 & 0 & 0 & 0 & $62.24 \pm 0.044$ \\
\hline 2 & 4058 & 42 & 0.657 & 0.037 & 0.575 & 0.0325 & $63.48 \pm 0.03$ \\
\hline 3 & 3976 & 83 & 1.235 & 0.067 & 1.159 & 0.0635 & $64.8 \pm 0.014$ \\
\hline 4 & 3824 & 159 & 2.41 & 0.123 & 2.309 & 0.119 & $67.41 \pm 0.089$ \\
\hline 5 & 3728 & 207 & 3.16 & 0.156 & 3.08 & 0.1528 & $69.49 \pm 0.006$ \\
\hline 6 & 3656 & 243 & 3.85 & 0.184 & 3.69 & 0.1776 & $70.76 \pm 0.1$ \\
\hline 7 & 3550 & 296 & 4.8 & 0.219 & 4.63 & 0.213 & $73.61 \pm 0.055$ \\
\hline 8 & 3452 & 345 & 6.04 & 0.261 & 5.552 & 0.245 & $76.06 \pm 0.14$ \\
\hline 9 & 3388 & 377 & 6.75 & 0.283 & 6.182 & 0.265 & $77.5 \pm 0.11$ \\
\hline 10 & 3314 & 414 & 7.47 & 0.304 & 6.94 & 0.288 & $79.7 \pm 0.19$ \\
\hline 11 & 3222 & 460 & 8.57 & 0.334 & 7.931 & 0.317 & $82.06 \pm 0.25$ \\
\hline 12 & 3108 & 517 & 9.745 & 0.36 & 9.24 & 0.351 & $84.35 \pm 0.143$ \\
\hline 13 & 3038 & 552 & 10.66 & 0.384 & 10.09 & 0.371 & $85.67 \pm 0.183$ \\
\hline 14 & 2960 & 591 & 11.83 & 0.409 & 11.09 & 0.3935 & $86.9 \pm 0.04$ \\
\hline 15 & 2868 & 637 & 13.49 & 0.44 & 12.339 & 0.419 & $87.83 \pm 0.25$ \\
\hline 16 & 2762 & 690 & 15.34 & 0.47 & 13.879 & 0.448 & $88.03 \pm 0.88$ \\
\hline 17 & 2636 & 753 & 17.37 & 0.504 & 15.87 & 0.481 & $88.77 \pm 0.42$ \\
\hline 18 & 2486 & 828 & 19.98 & 0.54 & 18.503 & 0.519 & $90.35 \pm 0.6$ \\
\hline 19 & 2368 & 887 & 24.6 & 0.59 & 20.81 & 0.549 & $93.4 \pm 2.157$ \\
\hline 20 & 2232 & 955 & 26.74 & 0.61 & 23.77 & 0.581 & $97.6 \pm 1.46$ \\
\hline 21 & 2122 & 1010 & 30.396 & 0.64 & 26.44 & 0.607 & $102.53 \pm 0.46$ \\
\hline $22^{\mathrm{a}}$ & 2109 & 421 & 11.48 & 0.4018 & 11.09 & 0.3935 & $86.9 \pm 0.59$ \\
\hline
\end{tabular}

a The solution slab in this system is $3 \mathrm{~nm} \times 3 \mathrm{~nm} \times 10 \mathrm{~nm}$ and the simulation box is $3 \mathrm{~nm} \times 3 \mathrm{~nm} \times 30 \mathrm{~nm}$.

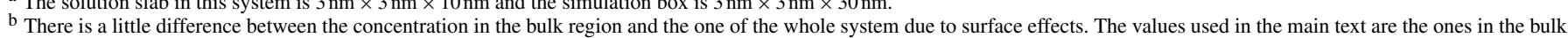
region.
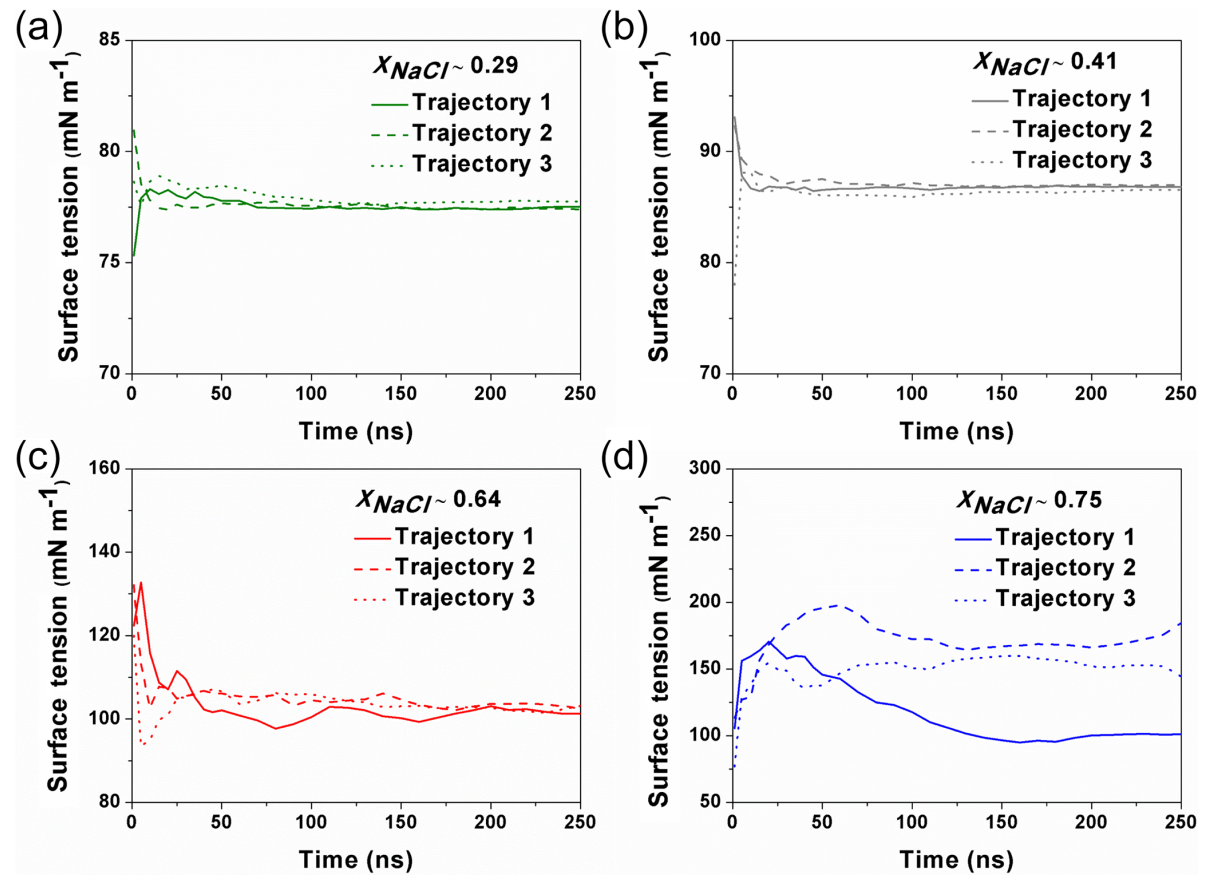

Figure 1. The calculated surface tension at different simulation time from different trajectories. For the solution with $x_{\mathrm{NaCl}} \leq 0.64$ (a-c), the surface tension become steadily stabilized after $\sim 100-150 \mathrm{~ns}$, and different individual simulation runs converge to a similar result. When $x_{\mathrm{NaCl}}>0.64\left(\mathbf{d} ;\right.$ here $\left.x_{\mathrm{NaCl}}=0.75\right)$, the surface tension keeps fluctuating and the final values from different individual simulations cannot be converged even after $250 \mathrm{~ns}$. 


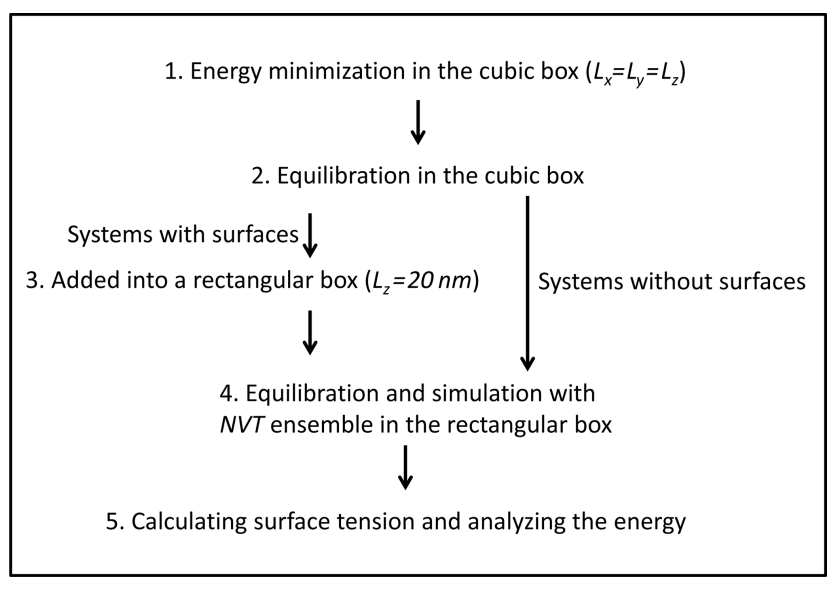

Figure 2. Schematic diagram of the different steps performed in the MD simulation.

the approach of Dutcher et al. (2010) assuming a linear relationship between surface tension of molten $\mathrm{NaCl}$ and temperature. With this approach, we retrieve the surface tension of molten $\mathrm{NaCl}$ at $298.15 \mathrm{~K}$ by extrapolating the simulated surface tension of molten $\mathrm{NaCl}$ in the temperature range of 1000 to $1700 \mathrm{~K}$. Note that, in principle, non-linearity could still be possible at very high degrees of supercooling (e.g., close to or at room temperature) for the molten salts, which may introduce uncertainties to the offset obtained by the extrapolation.

The simulation procedure we followed is the following (Fig. 2): (1) systems were firstly energetically minimized by the steepest descent method (Stillinger and Weber, 1985). (2) Solutions were equilibrated in the NVT ensemble (constant-temperature, constant-volume) and NPT ensemble (constant-temperature, constant-pressure) (pressure $=1 \mathrm{bar}$ ) with periodic boundary conditions in three directions. The temperature was controlled by using the Nosé-Hoover thermostat (Nosé, 1984; Hoover, 1985). The box volume change due to the variation in density at different temperatures, and in our case the length of the cubic box varied from 4.9 to $5.1 \mathrm{~nm}$. (3) The box was elongated along the $z$ direction with $L_{z}=20 \mathrm{~nm}$ to create two interfacial regions. (4) The solution was equilibrated and simulated with the NVT ensemble in the rectangular parallelepiped box at the corresponding temperature. (5) Systems without surfaces were also simulated for further energy analysis, and the trajectories obtained from step 2 were simulated with NPT ensemble. (6) All simulations were carried out for at least $200 \mathrm{~ns}$, which is much longer than that in previous studies (a few nanoseconds; Jungwirth and Tobias, 2000; Neyt et al., 2013), because the system that we were dealing with is much more concentrated. A 1 fs time step was adopted and conformations for analysis were saved every 2 ps. Both electrostatic interactions and van der Waals interactions were calculated using the particle mesh Ewald (PME) algorithm, which has been proven to be a good choice for accurate calculation of long-range interactions (Essmann et al., 1995; Fischer et al., 2015). To test the reproducibility, all the systems were simulated 3 times, and the respective statistical error bars were provided.

In our simulation, the Joung-Cheatham (JC) force field for $\mathrm{NaCl}$ (Joung and Cheatham III, 2009) with SPC/E water model (Berendsen et al., 1987) was applied to simulate the $\mathrm{NaCl}$ solution and molten $\mathrm{NaCl}$. The solubility at $298.15 \mathrm{~K}$ based on the JC force field with SPC/E model has been determined as $3.7 \pm 0.2 \mathrm{~mol} \mathrm{~kg}^{-1}$ (Moučka et al., 2013; Mester and Panagiotopoulos, 2015; Espinosa et al., 2016), which to the best of our knowledge is the value closest to the experimental value of solubility $\left(\sim 6.15 \mathrm{~mol} \mathrm{~kg}^{-1}\right)$. Therefore, this force field is appropriate to use to study the concentration dependence of properties. More details about the history of the attempts to correctly calculate the quantity by molecular simulation can be found in the review by Nezbeda et al. (2016).

\subsection{Calculation of surface tension}

Based on results from MD simulations, the surface tension was calculated by using the mechanical definition of the atomic pressure (Alejandre et al., 1995):

$\sigma_{\mathrm{MD}}=0.5 L_{z}\left[\left\langle P_{z z}\right\rangle-0.5\left(\left\langle P_{x x}\right\rangle+\left\langle P_{y y}\right\rangle\right)\right]$,

where $\sigma_{\mathrm{MD}}$ can represent the surface tension of molten $\mathrm{NaCl}$ $\left(\sigma_{\mathrm{NaCl}}\right), \mathrm{NaCl}$ solution $\left(\sigma_{\mathrm{NaCl}, \text { sol }}\right)$ or pure water $\left(\sigma_{\mathrm{water}}\right) ; L_{z}$ is the length of the simulation cell in the longest direction (along $z$ axis) and $P_{a a}(a=x, y, z)$ denotes the diagonal component of the pressure tensor. The $\langle\ldots\rangle$ refers to the time average. The factor 0.5 outside the squared brackets takes into account the two interfaces in the system. Only the stable values were taken as our calculated surface tension.

\subsection{Energy analysis}

The excess surface enthalpy denotes the additional enthalpy in the system due to the creation of surfaces. It can be calculated as the difference of enthalpy between solutions with and without surfaces (Bahadur et al., 2007),

$\Delta H=H_{b_{-} s}-H_{b}$,

where $H_{b \_s}$ is the total enthalpy of simulated systems with surfaces and $H_{b}$ is the total enthalpy of simulated systems without surfaces. As the kinetic energy is the same for systems with or without surfaces and the difference of $p V$ can be ignored, $\Delta H$ can be presented as

$\Delta H=E_{b_{-} s}-E_{b}$,

where $E_{b_{-} s}$ and $E_{b}$ are the potential energy of the system with and without surfaces.

Then the surface tension can be determined by the excess surface free energy per unit area as in Eq. (4) (Davidchack 

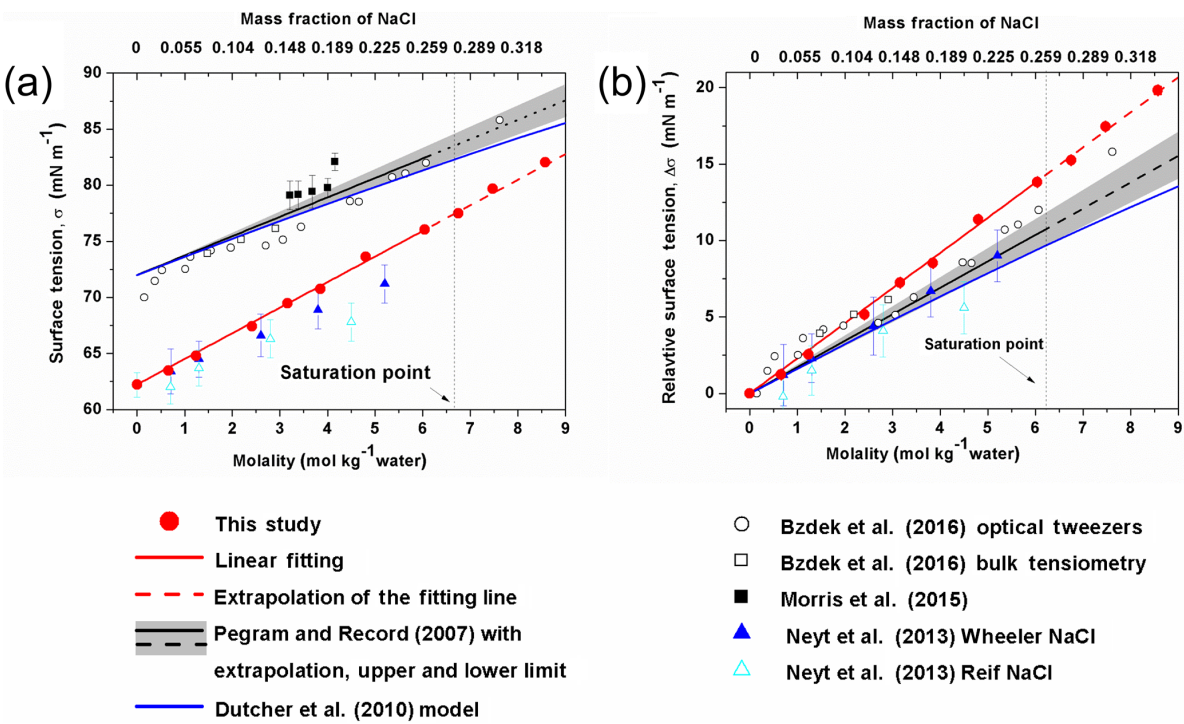

Figure 3. Surface tension (a) and relative surface tension (b) defined as $\Delta \sigma=\sigma_{\text {solution }}-\sigma_{\text {water }}$ as a function of the concentration of NaCl. The $\sigma_{\text {water }}$ in the Morris et al. (2015) study was not determined, thus the corresponding $\Delta \sigma$ is not shown in (b).

and Laird, 2003):

$\sigma=\frac{\Delta G}{A}=\frac{\Delta H-T \cdot \Delta S}{A}$

where $\Delta G$ is the increased part of free energy due to the creation of surfaces, $A$ is the total area of the surface we created, so $A=2 \times a$ and $a$ is the area of each created surface. $\Delta S$ is the excess surface entropy. We then can retrieve $\Delta S$ by using the data of enthalpy and surface tension:

$\Delta S=\frac{\Delta H-\sigma \cdot A}{T}$

where $\Delta H$ and $T \cdot \Delta S$ per unit area $\left(\frac{\Delta H}{A}\right.$ and $\left.\frac{T \cdot \Delta S}{A}\right)$ are obtained as the enthalpic and entropic part of the contributions to the net surface tension, which will be used to explain the change of surface tension along with the mass fraction of $\mathrm{NaCl}\left(x_{\mathrm{NaCl}}\right)$.

\section{Results and discussion}

\subsection{Water-dominated regime $\left(x_{\mathrm{NaCl}}<\sim 0.39\right)$}

In Fig. 3a, the calculated surface tension of $\mathrm{NaCl}$ aqueous solution $\left(\sigma_{\mathrm{NaCl}, \mathrm{sol}}\right)$ is compared with experimentally determined values (Jarvis and Scheiman, 1968; Johansson and Eriksson, 1974; Aveyard and Saleem, 1976; Weissenborn and Pugh, 1995; Matubayasi et al., 2001; Pegram and Record, 2006, 2007; Morris et al., 2015; Bzdek et al., 2016) in the subsaturated concentration range (molality of $\mathrm{NaCl}$ solution from 0 to $6.15 \mathrm{~mol} \mathrm{~kg}^{-1}$ and $x_{\mathrm{NaCl}}$ from 0 to $\sim 0.265$ ). At $298.15 \mathrm{~K}$, both model simulation (red solid points and fit line in Fig. 3a) and experimental observation (black line in
Fig. 3a) reveal a linear dependence of surface tension on solution concentration at molality scale, with a very similar slope (2.1 versus $1.73 \pm 0.17$, respectively). Systematic underestimation, however, exists in the simulated $\sigma_{\mathrm{NaCl} \text {,sol }}$. The previous MD simulations by Neyt et al. (2013) have also reported a similar result for the solution whose concentration ranges from 0 to $5.2 \mathrm{~mol} \mathrm{~kg}^{-1}$ by using the same water model (SPC/E) but two different $\mathrm{NaCl}$ force fields, i.e., Wheeler $\mathrm{NaCl}$ (solid dark-blue triangle in Fig. 3a) and Relf $\mathrm{NaCl}$ (open light-blue triangle in Fig. 3a). Bhatt et al. (2004) also used the Wheeler $\mathrm{NaCl}$ model and SPC/E water model revealing a linear dependence and underestimation. We also subtracted the experimentally determined and the MD-simulated surface tension of pure water $\left(\sigma_{\text {water }}\right)$ from the observed and modeled $\sigma_{\mathrm{NaCl} \text {,sol }}$, respectively. The relative increase in surface tension $\left(\Delta \sigma=\sigma_{\mathrm{NaCl} \text {,sol }}-\sigma_{\text {water }}\right)$ from models and experiments converge nicely (Fig. 3b), and the former is only a little higher than the latter. The MD simulation is able to reproduce the increment in the growth of surface tension from pure water due to the addition of solute $\mathrm{NaCl}$, although the predicted absolute value of $\sigma_{\mathrm{NaCl} \text {,sol }}$ is systematically underestimated, which may mainly be attributed to the discrepancy between observed $\sigma_{\text {water }}$ and the modeled ones from the SPC/E water model.

By performing MD simulations in the supersaturated concentration range, we found that this linear relationship still holds beyond the saturation point until $x_{\mathrm{NaCl}}$ of $\sim 0.39$ (Fig. 4). As mentioned above, the laboratory experiments with elevated $\mathrm{NaCl}$ aqueous droplet and the optical tweezer method show that the linear relationship between $\sigma_{\mathrm{NaCl} \text {,sol }}$ and $\mathrm{NaCl}$ concentration (molality scale) can be extended to $\sim 8 \mathrm{~mol} \mathrm{~kg}^{-1}$ (Fig. 3; Bzdek et al., 2016), corresponding to 

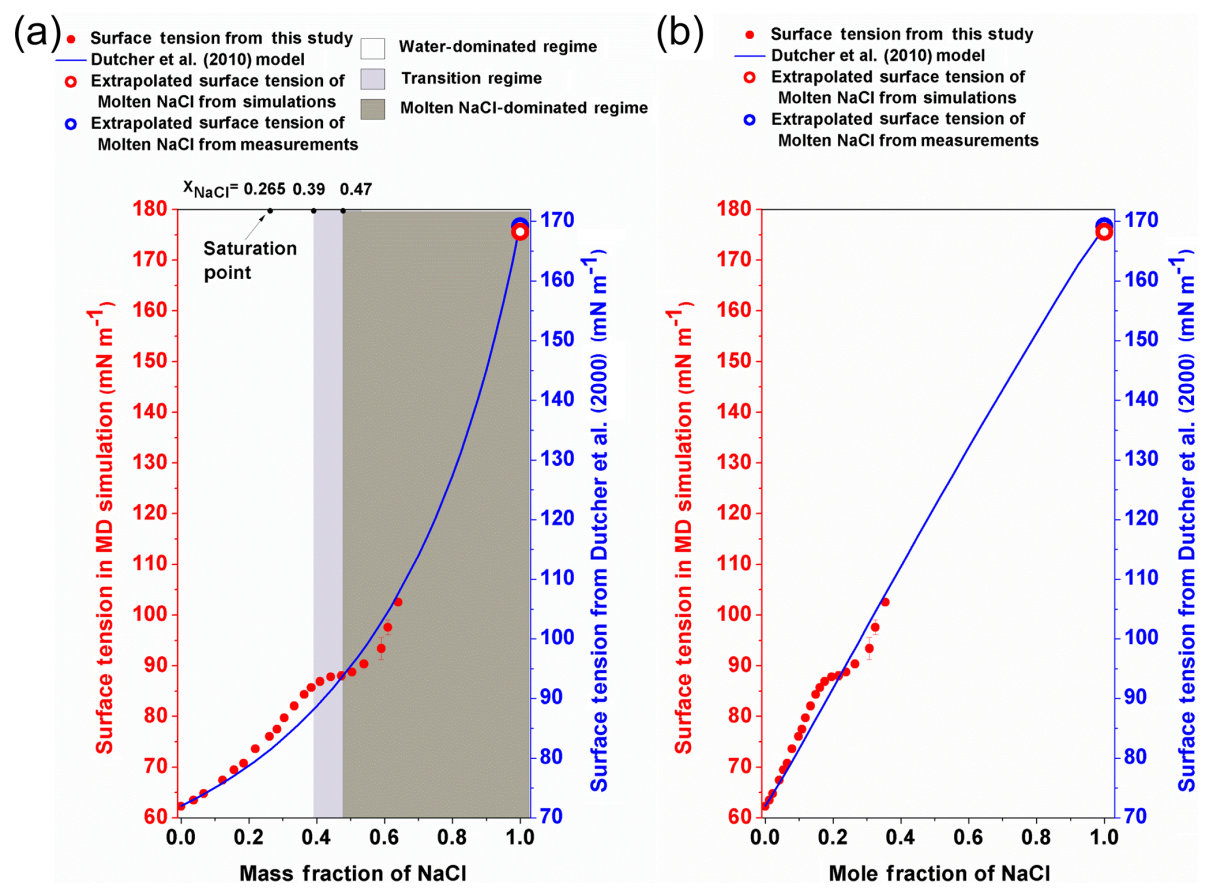

Figure 4. The surface tension of different-concentration $\mathrm{NaCl}$ solution. (a) The surface tension of $\mathrm{NaCl}$ solution against the mass fraction of $\mathrm{NaCl}$. The left red $y$ axis is for the data from MD simulation (red circle), and the right blue $y$ axis is for the Dutcher et al. (2010) model (blue solid line). The white, light grey and dark grey areas shade the water-dominated, transition and molten NaCl-dominated regimes, respectively. (b) The surface tension of $\mathrm{NaCl}$ solution is plotted against the mole fraction of $\mathrm{NaCl}$.

$x_{\mathrm{NaCl}}$ of $\sim 0.33$ (Fig. 4), which is consistent with our simulations.

\subsection{Transition regime $\left(x_{\mathrm{NaCl}}\right.$ from $\sim 0.39$ to $\left.\sim 0.47\right)$}

It was often found that surface tensions of single inorganic electrolyte aqueous solutions were linear functions of concentration (at the molality scale) over the moderate concentration range (Horvath, 1985; Dutcher et al., 2010). However, these simple relationships may not hold when the solutions become more concentrated. As shown in Fig. 4, start-

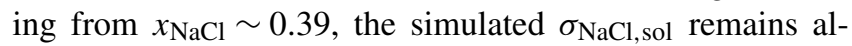
most unchanged until $x_{\mathrm{NaCl}}$ of $\sim 0.47$ (concentration upon efflorescence). This inflection point of $\sigma_{\mathrm{NaCl} \text {,sol }}$ at $x_{\mathrm{NaCl}}$ of $\sim 0.39$ is supported by those determined by the DKA approach (Cheng et al., 2015), where there is a large deviation of surface tension from the monotonic linear increase. Note that beyond $x_{\mathrm{NaCl}}$ of $\sim 0.47$, the simulated surface tension increases again (Fig. 4). This second inflection point, right at the concentration upon efflorescence, may imply a potential correlation with crystallization processes.

\subsection{Molten NaCl-dominated regime $\left(x_{\mathrm{NaCl}}>\sim 0.47\right)$}

Beyond the second inflection point $\left(x_{\mathrm{NaCl}}>0.47\right)$, the simu-

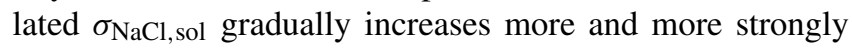
(Fig. 4). Unfortunately, due to the large fluctuation in the surface tension simulation (Fig. 1), we are not able to ex- tend our surface tension calculation in this way beyond $x_{\mathrm{NaCl}}$ of $\sim 0.64$. However, according to Dutcher et al. (2010), it is expected that the surface tension of the solution would ultimately approach the surface tension of the hypothetical molten solute (i.e., $x_{\mathrm{NaCl}}=1$ ) at the same temperature. This hypothesis has been found to be consistent with the DKA retrieval for a highly concentrated ammonium sulfate aqueous solution with molality of $\sim 380 \mathrm{~mol} \mathrm{~kg}^{-1}$ (Cheng et al., $2015)$. We thus also try to constrain the growth of $\sigma_{\mathrm{NaCl} \text {,sol }}$ by MD-simulated surface tension of molten $\mathrm{NaCl}\left(\sigma_{\mathrm{NaCl}}\right)$ at $298.15 \mathrm{~K}$.

Similar to the experimental results of Janz (1988), the simulated $\sigma_{\mathrm{NaCl}}$ is also linearly correlated with temperature from $1000 \mathrm{~K}$ (the simulated melting point of $\mathrm{NaCl}$ ) to $1700 \mathrm{~K}$, as shown in Fig. 5. Following Dutcher et al. (2010), a surface tension of $\sim 175.58 \mathrm{mN} \mathrm{m}^{-1}$ is obtained for the hypothetical molten $\mathrm{NaCl}$ at $298.15 \mathrm{~K}$ by linear extrapolation of the MD simulated $\sigma_{\mathrm{NaCl}}$ at higher temperature, which is very close to the $\sim 169.7 \mathrm{mN} \mathrm{m}^{-1}$ extrapolated from the experimental results (Dutcher et al., 2010). Combined with $\sigma_{\mathrm{NaCl}}=\sigma_{\mathrm{NaCl} \text {,sol }}\left(x_{\mathrm{NaCl}}=1\right)=\sim 175.58 \mathrm{mN} \mathrm{m}^{-1}$, the simulated $\sigma_{\mathrm{NaCl} \text {,sol }}$ in the concentration range of $x_{\mathrm{NaCl}}>0.47$ shows the tendency to ultimately approach the surface tension of melting $\mathrm{NaCl}$ at $298.15 \mathrm{~K}$, similar to the blue curve in Fig. 4 from the Dutcher et al. (2000) study. 


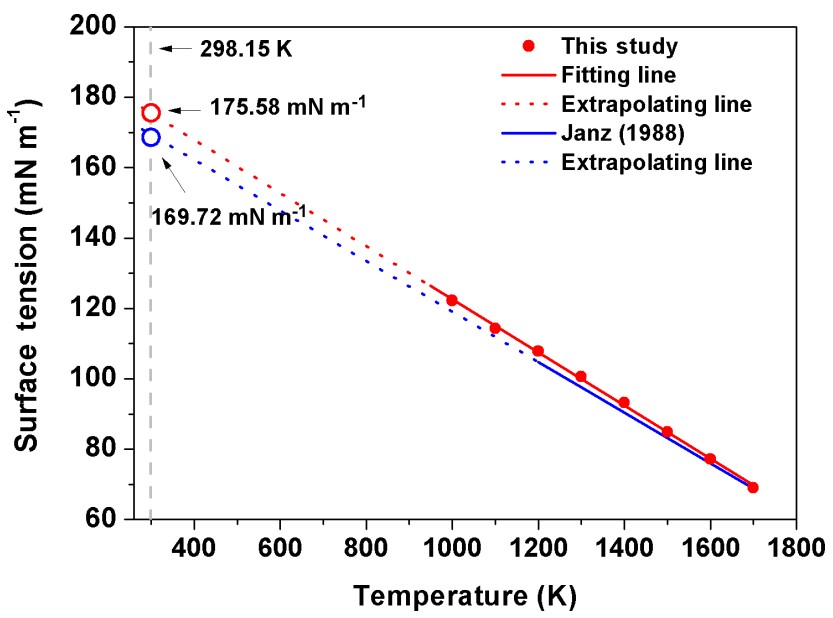

Figure 5. The surface tension of molten $\mathrm{NaCl}$ at different temperatures. The equation in Janz's study (1988) is $\sigma_{\mathrm{NaCl}}=-0.07188$. $T+191$ (blue solid line). The fitting line based on our data is $\sigma_{\mathrm{NaCl}}=-0.0755 \cdot T+198.09$ (red solid line). The red and blue open circles represent the extrapolated value of surface tension in simulation and reality, respectively.

\subsection{Physical chemistry behind the regimes}

In energetic analyses, surface tension was decomposed into excess surface enthalpy $\left(\frac{\Delta H}{A}\right)$ and excess surface entropy $\left(\frac{T \cdot \Delta S}{A}\right)$. Note that the increase in excess surface entropy $\left(\frac{T \cdot \Delta S}{A}\right)$ or decrease in $-\frac{T \cdot \Delta S}{A}$ will negatively contribute to the

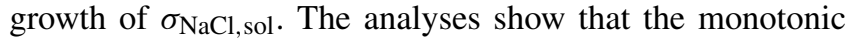
increase in surface tension in water-dominated concentration ranges $\left(x_{\mathrm{NaCl}}\right.$ from 0 to $\left.\sim 0.39\right)$ is driven by the increase in $\frac{\Delta H}{A}$ when the solution becomes concentrated (Fig. 6). When the solution gets concentrated, $\frac{\Delta H}{A}$ first increases slightly with enhanced increasing rate at $x_{\mathrm{NaCl}}>\sim 0.2$ and in the supersaturated regime up to $x_{\mathrm{NaCl}}$ of $\sim 0.39$. $-\frac{T \cdot \Delta S}{A}$ behaves differently, it remains almost constant at about $-45 \mathrm{mN} \mathrm{m}^{-1}$ first and only starts to decrease at $x_{\mathrm{NaCl}} \sim 0.2$. This way, in this concentration range $\left(x_{\mathrm{NaCl}}\right.$ from 0 to $\left.\sim 0.39\right)$, the increase in excess surface enthalpy outnumbers the increase in excess surface entropy and thus this physicochemical regime can be understood as an excess surface enthalpy-driving process.

The stable surface tension in the transition-regime concentration range $\left(x_{\mathrm{NaCl}}\right.$ from $\sim 0.39$ to $\left.\sim 0.47\right)$ is attributed to the fact that $-\frac{T \cdot \Delta S}{A}$ and $\frac{\Delta H}{A}$ are both almost unchanged. Figure 6 shows that in the concentration above $x_{\mathrm{NaCl}}$ of $\sim 0.39$, the increase in $\frac{\Delta H}{A}$ significantly slows down and stabilizes at $\sim 145 \mathrm{mN} \mathrm{m}^{-1}$ when the mass fraction approaches the efflorescence point. During this period, $-\frac{T \cdot \Delta S}{A}$ keeps nearly unchanged, which results in a corresponding $\sigma_{\mathrm{NaCl} \text {,sol }}$ almost independent of the solution concentration change.

Here, we present a potential explanation for the stability of surface tension in this region from the structural analysis.
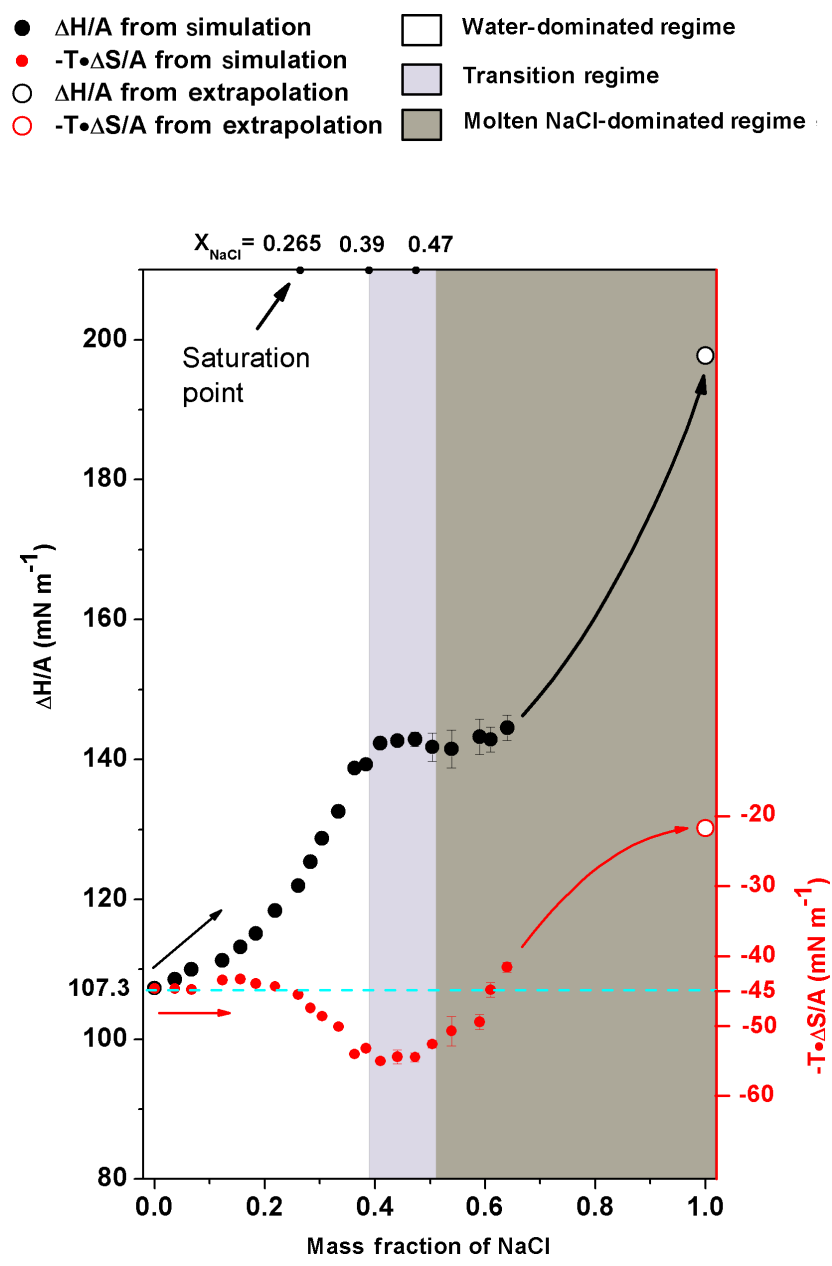

Figure 6. The excess surface enthalpy and entropy per unit area $\left(\frac{\Delta H}{A}\right.$ and $\frac{T \cdot \Delta S}{A}$ ) of different $\mathrm{NaCl}$ solution concentrations. $\frac{\Delta H}{A}$ (black circles) and $-\frac{T \cdot \Delta S}{A}$ (red circles) are shown as a function of mass fraction of $\mathrm{NaCl}$. The solid circles are obtained from simulation directly, and the open circles are obtained from the extrapolation of corresponding properties of molten $\mathrm{NaCl}$. The cyan dashed line is only an auxiliary line for clearer view. Shaded areas are the same as in Fig. 4.

The ratio of $\mathrm{Na}^{+}$concentration at different positions to the average concentration of the whole system $\left(C_{z} / C_{\text {average }}\right)$ in different solutions is shown in Fig. 7a. The three blue-toned lines represent the ratio of solution in the transition regime with $x_{\mathrm{NaCl}}$ from $\sim 0.39$ to $\sim 0.47$. All of them have apophyses (significant rise) near the surface and these apophyses almost overlap with each other. This phenomenon suggests that the solute in these solutions enriches close to the surface and the degree of enrichment is almost the same for the differentconcentration solution. Here, we denote the significant difference of the solute concentration in bulk region and on surface as a type of liquid-liquid partitioning. To check if this partitioning is dependent on the size of the solution slab, we calculate the corresponding value of a $3 \mathrm{~nm} \times 3 \mathrm{~nm} \times 10 \mathrm{~nm}$ 

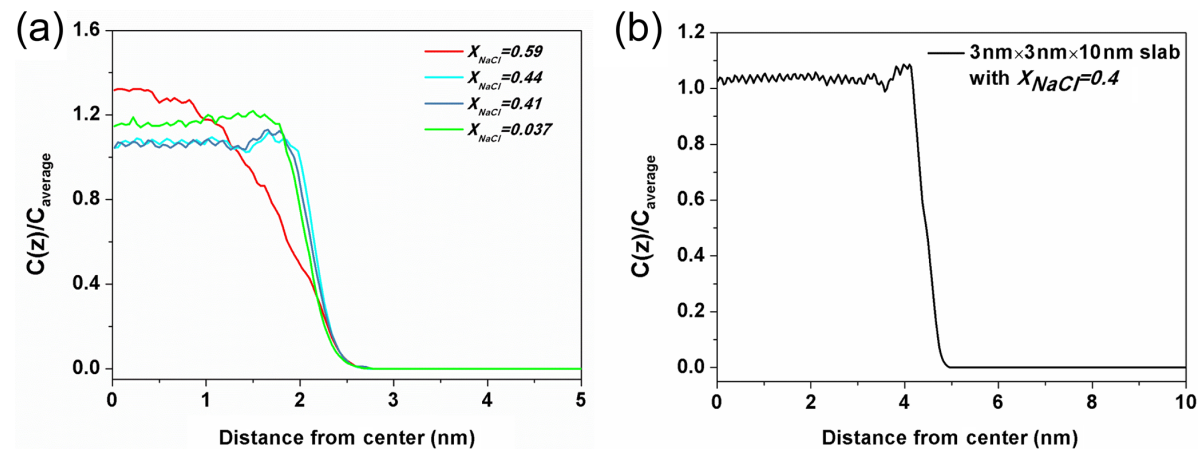

Figure 7. The ratio of $\mathrm{Na}^{+}$concentration at different positions $\left(C_{z}\right)$ to the average concentration of the whole system $\left(C_{\text {average }}\right)$. (a) The solution with $x_{\mathrm{NaCl}}=0.59$ (red line) is on behalf of the solution in the molten $\mathrm{NaCl}$-dominated regime (red line), the solution $x_{\mathrm{NaCl}}=0.44$ and 0.41 (blue lines) represent the solution in transition regime and the solution $x_{\mathrm{NaCl}}=0.037$ (green line) represents the solution in the water-dominated regime. (b) The density profile obtained from a $3 \mathrm{~nm} \times 3 \mathrm{~nm} \times 10 \mathrm{~nm}$ solution slab in which $\mathrm{NaCl}$ mass fraction is about 0.4 .

solution slab with $x_{\mathrm{NaCl}}$ of 0.4 (Fig. 7b). There is still an apophysis near the surface, thus we can claim that the partitioning is independent of the size of the solution slab in the simulation. Note that this surface enrichment of $\mathrm{NaCl}$ does not mean that $\mathrm{NaCl}$ is enriched right on top of the solution surface. Actually the density profile of water extends about $0.2 \mathrm{~nm}$ beyond that of $\mathrm{NaCl}$ towards the vapor region. By contrast, the solution with $x_{\mathrm{NaCl}}>0.47$ or $<0.39$ do not have this type of partitioning as shown by the red and green lines. This comparison implies that the stability of surface tension of solution with $x_{\mathrm{NaCl}}$ from $\sim 0.39$ to $\sim 0.47$ is related to the "bulk-surface" partitioning. This interpretation is only a conjecture, and more studies are needed to further examine this phenomenon and interpretation. The shallow minimum in the density profile for $x_{\mathrm{NaCl}}$ between 0.39 and 0.47 to the left of the maximum is somewhat unexpected, and one might expect equilibration problems. However, we have checked that this structural feature develops already during the first $10 \mathrm{~ns}$ of the MD simulation, and does not change at all during the residual $200 \mathrm{~ns}$. Surface enrichment of $\mathrm{NaCl}$ can be expected, however, when the solubility limit of the water-rich solution in the bulk is reached. Very roughly, such phenomena are analogous to interfacial wetting phenomena such as surface melting of crystals (Frenken and Van der Veen, 1985), which is sometimes observed when the temperature is raised towards the triple point. In our case, the enrichment zone of $\mathrm{NaCl}$ (which is about $0.4 \mathrm{~nm}$ thick in Fig. 7) would be a precursor effect to the (metastable) NaClrich bulk solution. Tentatively, one may correlate the formation of the enrichment zone with the stability of the surface entropy in this region via the entropy of mixing. At the same time, the surface enhancement of ions may be related to the phenomenon of efflorescence.

As shown in Fig. 6, when a solution gets more concentrated from $x_{\mathrm{NaCl}}$ of $\sim 0.47$ to $\sim 0.64$, the $\frac{\Delta H}{A}$ slightly increases from the plateau of $\sim 145 \mathrm{mN} \mathrm{m}^{-1}$ but the change is only $\sim 5 \mathrm{mNm}^{-1}$. The $-\frac{T \cdot \Delta S}{A}$ keeps increasing. So dur- ing this period, both the surface excess enthalpy and entropy terms contribute to the growth of $\sigma_{\mathrm{NaCl}, \text { sol }}$. To constrain the energetic analyses, the $\frac{T \cdot \Delta S}{A}$ and $\frac{\Delta H}{A}$ were also calculated for the molten $\mathrm{NaCl}$ at $298.15 \mathrm{~K}$. According to Fig. 5, we have $\sigma_{\mathrm{NaCl}}=-0.0755 \cdot T+198.09$; then we can get $\frac{\Delta S_{\mathrm{NaCl}}}{A}=0.0755 \mathrm{mN} \mathrm{m}^{-1} \mathrm{~K}^{-1}$ because of $\frac{\Delta S(T)}{A}=\frac{-\mathrm{d} \sigma(T)}{\mathrm{d} T}$ (Landau and Lifshitz, 1969). Therefore, for molten $\mathrm{NaCl}$ $\left(x_{\mathrm{NaCl}}=1.0\right), \frac{T \cdot \Delta S_{\mathrm{NaCl}}}{A}$ at $298.16 \mathrm{~K}$ is $22.15 \mathrm{mN} \mathrm{m}^{-1}$, and $\frac{\Delta H_{\mathrm{NaCl}}}{A}$ at $298.15 \mathrm{~K}^{\text {is }} 198.09 \mathrm{mN} \mathrm{m}^{-1}$ (Fig. 6). Here, we used the derivative of the temperature-surface tension relation to calculate the excess surface entropy, and more discussions about the comparison of these methods can be found in the Supplement (Fig. S1). As can be seen in Fig. 6, it is expected that the excess surface enthalpy term will still have a large amount (about more than $50 \mathrm{mN} \mathrm{m}^{-1}$ ) to grow until approaching $\frac{\Delta H}{A}$ of molten $\mathrm{NaCl}$ at $298.15 \mathrm{~K}$. It is similar for the surface excess entropy term while the increment is smaller. Thus, the fast increase in $\sigma_{\mathrm{NaCl} \text {,sol }}$ in the concentration of $x_{\mathrm{NaCl}}$ from $\sim 0.47$ to 1 can be assumed to be a process driven by excess surface enthalpy and excess surface entropy.

\section{Conclusion}

The analysis based on the calculated surface tension confirms the basic concept of the Dutcher et al. (2010) semiempirical model, while unfolding a more detailed global landscape of concentration dependence of surface tension of aqueous $\mathrm{NaCl}$ solution and its driving forces: (1) a water-dominated regime $\left(x_{\mathrm{NaCl}}\right.$ from 0 to $\sim 0.39$; at low concentrations ions are solvated by the water molecules, which means that waterstructures/hydration shells are formed around ions); (2) a transition regime $\left(x_{\mathrm{NaCl}}\right.$ from $\sim 0.39$ to $\left.\sim 0.47\right)$; and (3) a molten $\mathrm{NaCl}$-dominated regime $\left(x_{\mathrm{NaCl}}\right.$ from $\sim 0.47$ to 1 , at very high salt concentration water molecules are solvated by the ions, which means that a salt-structure is formed around the water molecules). Note that our result may not exactly reflect the real mode of surface tension of $\mathrm{NaCl}$ solution along 
the concentration, but it does imply the concept of a nonmonotonic change of surface tension. One must be aware that for nucleation processes in the atmosphere other chemical compounds also matter, and will require future study. Also, mixed salt solutions would be very interesting, and can in principle be studied with similar simulation methods as applied here; however, this task must be left to future work.

Data availability. Readers who are interested in the data should contact the authors: Yafang Cheng (yafang.cheng@mpic.de), Hang Su (h.su@mpic.de) or Xiaoxiang Wang (xiaoxiang.wang@mpic.de).

Supplement. The supplement related to this article is available online at: https://doi.org/10.5194/acp-18-17077-2018-supplement.

Author contributions. YC and HS conceived and led the study. XW performed the MD simulation and analyzed the data. XW, YC, KB and HS interpreted the results. UP and CC discussed the results and commented on the manuscript. XW, KB, YC, CC and HS wrote the manuscript with input from all coauthors.

Competing interests. The authors declare that they have no conflict of interest.

Acknowledgements. This study is supported by the Max Planck Society (MPG). Xiaoxiang Wang acknowledges the support from China Scholarship Council (CSC, 201406190170). Yafang Cheng acknowledges the Minerva Program from MPG.

The article processing charges for this open-access publication were covered by the Max Planck Society.

Edited by: Maria Cristina Facchini

Reviewed by: two anonymous referees

\section{References}

Abraham, M. J., Murtola, T., Schulz, R., Páll, S., Smith, J. C., Hess, B., and Lindahl, E.: GROMACS: High performance molecular simulations through multi-level parallelism from laptops to supercomputers, SoftwareX., 1, 19-25, 2015.

Alejandre, J., Tildesley, D. J., and Chapela, G. A.: Molecular dynamics simulation of the orthobaric densities and surface tension of water, J. Chem. Phys., 102, 4574-4583, 1995.

Aveyard, R. and Saleem, S. M.: Interfacial tensions at alkaneaqueous electrolyte interfaces, J. Am. Chem. Soc., 72, 16091617, 1976.

Bahadur, R., Russell, L. M., and Alavi, S.: Surface tensions in NaClwater-air systems from MD simulations, J. Phys. Chem. B, 111, 11989-11996, 2007.
Berendsen, H., Grigera, J., and Straatsma, T.: The missing term in effective pair potentials, J. Phys. Chem., 91, 6269-6271, 1987.

Bhatt, D., Newman, J., and Radke, C.: Molecular dynamics simulations of surface tensions of aqueous electrolytic solutions, J. Phys. Chem. B, 108, 9077-9084, 2004.

Biskos, G., Malinowski, A., Russell, L., Buseck, P., and Martin, S.: Nanosize effect on the deliquescence and the efflorescence of sodium chloride particles., Aerosol Sci. Tech., 40, 97-106, 2006.

Bzdek, B. R., Power, R. M., Simpson, S. H., Reid, J. P., and Royall, C. P.: Precise, contactless measurements of the surface tension of picolitre aerosol droplets, Chem. Sci., 7, 274-285, 2016.

Chen, Y., Cheng, Y., Ma, N., Wolke, R., Nordmann, S., Schüttauf, S., Ran, L., Wehner, B., Birmili, W., van der Gon, H. A. C. D., Mu, Q., Barthel, S., Spindler, G., Stieger, B., Müller, K., Zheng, G.-J., Pöschl, U., Su, H., and Wiedensohler, A.: Sea salt emission, transport and influence on sizesegregated nitrate simulation: a case study in northwestern Europe by WRF-Chem, Atmos. Chem. Phys., 16, 12081-12097, https://doi.org/10.5194/acp-16-12081-2016, 2016.

Cheng, Y., Su, H., Koop, T., Mikhailov, E., and Pöschl, U.: Size dependence of phase transitions in aerosol nanoparticles, Nat. Commun., 6, 5923, 2015.

Davidchack, R. L. and Laird, B. B.: Direct calculation of the crystal-melt interfacial free energies for continuous potentials: Application to the Lennard-Jones system, J. Chem. Phys., 118, 7651-7657, 2003.

Dutcher, C. S., Wexler, A. S., and Clegg, S. L.: Surface tensions of inorganic multicomponent aqueous electrolyte solutions and melts, J. Phys. Chem. A, 114, 12216-12230, 2010.

Espinosa, J., Young, J., Jiang, H., Gupta, D., Vega, C., Sanz, E., Debenedetti, P., and Panagiotopoulos, A.: On the calculation of solubilities via direct coexistence simulations: Investigation of $\mathrm{NaCl}$ aqueous solutions and Lennard-Jones binary mixtures, J. Chem. Phys., 145, 154111, https://doi.org/10.1063/1.4964725, 2016.

Essmann, U., Perera, L., Berkowitz, M. L., Darden, T., Lee, H., and Pedersen, L. G.: A smooth particle mesh Ewald method, J. Chem. Phys., 103, 8577-8593, 1995.

Finlayson-Pitts, B.: The tropospheric chemistry of sea salt: A molecular-level view of the chemistry of $\mathrm{NaCl}$ and $\mathrm{NaBr}$, Chem. Rev., 103, 4801-4822, 2003.

Fischer, N. M., van Maaren, P. J., Ditz, J. C., Yildirim, A., and van der Spoel, D.: Properties of organic liquids when simulated with long-range Lennard-Jones interactions, J. Chem. Theory Comput., 11, 2938-2944, 2015.

Frenken, J. W. M. and Van der Veen, J. F.: Observation of surface melting, Phys. Rev. Lett., 54, 134-137, 1985.

Ghorai, S., Wang, B., Tivanski, A., and Laskin, A.: Hygroscopic properties of internally mixed particles composed of $\mathrm{NaCl}$ and water-soluble organic acids, Environ. Sci. Technol., 48, 2234 2241, 2014.

Harkins, W. D. and Brown, F.: The determination of surface tension (free surface energy), and the weight of falling drops: The surface tension of water and benzene by the capillary height method, J. Am. Chem. Soc., 41, 499-524, 1919.

Hoover, W. G.: Canonical dynamics: equilibrium phase-space distributions, Phys. Rev. A, 31, 1695, https://doi.org/10.1103/PhysRevA.31.1695, 1985. 
Horvath, A. L.: Handbook of aqueous electrolyte solution physical properties, estimation and correlation methods, Ellis Horwood Series in Physical Chemistry, Ellis Horwood Limited, New York, 1985.

Janz, G. J.: Thermodynamic and transport properties for molten salts: correlation equations for critically evaluated density, surface tension, electrical conductance, and viscosity data, Amer. Inst. of Phys., New York, 1988.

Jarvis, N. L. and Scheiman, M. A.: Surface potentials of aqueous electrolyte solutions, J. Phys. Chem., 72, 74-78, 1968.

Johansson, K. and Eriksson, J. C.: $\gamma$ and $\mathrm{d} \gamma / \mathrm{d} T$ measurements on aqueous solutions of 1, 1-electrolytes, J. Colloid Interf. Sci., 49, 469-480, 1974.

Joung, I. S. and Cheatham III, T. E.: Molecular dynamics simulations of the dynamic and energetic properties of alkali and halide ions using water-model-specific ion parameters, J. Phys. Chem. B, 113, 13279-13290, 2009.

Jungwirth, P. and Tobias, D. J.: Surface effects on aqueous ionic solvation: A molecular dynamics simulation study of $\mathrm{NaCl}$ at the air/water interface from infinite dilution to saturation, J. Phys. Chem. B, 104, 7702-7706, 2000.

Kumar, A.: Aqueous guanidinium salts: Part II. Isopiestic osmotic coefficients of guanidinium sulphate and viscosity and surface tension of guanidinium chloride, bromide, acetate, perchlorate and sulphate solutions at 298.15 K, Fluid Phase Equilibr., 180, 195-204, 2001.

Landau, L. D. and Lifshitz, E. M.: Statistical physics, Pergamon press, Oxford, 1969.

Levin, Y. and Flores-Mena, J.: Surface tension of strong electrolytes, EPL, 56, 187-192, 2001.

Lewis, E. R. and Schwartz, S. E.: Sea salt aerosol production: mechanisms, methods, measurements, and models-A critical review, American Geophysical Union, Washington, D.C., 2004.

Li, Z. and Lu, B. C.-Y.: Surface tension of aqueous electrolyte solutions at high concentrations - representation and prediction, Chem. Eng. Sci., 56, 2879-2888, 2001.

Li, Z.-B., Li, Y.-G., and Lu, J.-F.: Surface tension model for concentrated electrolyte aqueous solutions by the Pitzer equation, Ind. Eng. Chem. Res., 38, 1133-1139, 1999.

Martin, S. T.: Phase transitions of aqueous atmospheric particles, Chem. Rev., 100, 3403-3454, 2000.

Matubayasi, N., Tsunetomo, K., Sato, I., Akizuki, R., Morishita, T., Matuzawa, A., and Natsukari, Y.: Thermodynamic quantities of surface formation of aqueous electrolyte solutions: IV. Sodium halides, anion mixtures, and sea water, J. Colloid Interf. Sci., 243, 444-456, 2001.

Mester, Z. and Panagiotopoulos, A Z.: Mean ionic activity coefficients in aqueous $\mathrm{NaCl}$ solutions from molecular dynamics simulations, J. Chem. Phys., 142, 044507, https://doi.org/10.1063/1.4906320, 2015.

Morris, H. S., Grassian, V. H., and Tivanski, A. V.: Humiditydependent surface tension measurements of individual inorganic and organic submicrometre liquid particles, Chem. Sci., 6, 32423247, 2015.
Moučka, F., Nezbeda, I., and Smith, W. R.: Molecular force field development for aqueous electrolytes: 1 . Incorporating appropriate experimental data and the inadequacy of simple electrolyte force fields based on Lennard-Jones and point charge interactions with Lorentz-Berthelot rules, J. Chem. Theory Comput., 9, 5076-5085, 2013.

Neyt, J.-C., Wender, A., Lachet, V., Ghoufi, A., and Malfreyt, P.: Prediction of the concentration dependence of the surface tension and density of salt solutions: atomistic simulations using Drude oscillator polarizable and nonpolarizable models, Phys. Chem. Chem. Phys., 15, 11679-11690, 2013.

Nezbeda, I., Moučka, F., and Smith, W. R.: Recent progress in molecular simulation of aqueous electrolytes: Force fields, chemical potentials and solubility, Mol. Phys., 114, 1665-1690, 2016.

Nosé, S.: A molecular dynamics method for simulations in the canonical ensemble, Mol. Phys., 52, 255-268, 1984.

Pegram, L. M. and Record, M. T.: Partitioning of atmospherically relevant ions between bulk water and the water/vapor interface, P. Natl. Acad. Sci. USA, 103, 14278-14281, 2006.

Pegram, L. M. and Record, M. T.: Hofmeister salt effects on surface tension arise from partitioning of anions and cations between bulk water and the air-water interface, J. Phys. Chem. B, 111, 5411-5417, 2007.

Richardson, C. and Snyder, T. D.: A study of heterogeneous nucleation in aqueous solutions, Langmuir, 10, 2462-2465, 1994.

Sada, E., Katoh, S., Yoshii, H., Yamanlshl, T., and Nakanlshl, A.: Performance of the gas bubble column in molten salt systems, Ind. Eng. Chem. Proc. Des. Dev., 23, 151-154, 1984.

Stillinger, F. H. and Weber, T. A.: Computer simulation of local order in condensed phases of silicon, Phys. Rev. B, 31, 52625271, 1985.

Vargaftik, N., Volkov, B., and Voljak, L.: International tables of the surface tension of water, J. Phys. Chem. Ref. Dat., 12, 817-820, 1983.

Wagner, R., Höhler, K., Möhler, O., Saathoff, H., and Schnaiter, M.: Crystallization and immersion freezing ability of oxalic and succinic acid in multicomponent aqueous organic aerosol particles, Geophys. Res. Lett., 42, 2464-2472, 2015.

Weissenborn, P. K. and Pugh, R. J.: Surface tension and bubble coalescence phenomena of aqueous solutions of electrolytes, Langmuir, 11, 1422-1426, 1995.

Weissenborn, P. K. and Pugh, R. J.: Surface tension of aqueous solutions of electrolytes: relationship with ion hydration, oxygen solubility, and bubble coalescence, J. Colloid Interf. Sci., 184, 550-563, 1996.

Wexler, A. S. and Clegg, S. L.: Atmospheric aerosol models for systems including the ions $\mathrm{H}^{+}, \mathrm{NH}_{4}^{+}, \mathrm{Na}^{+}, \mathrm{SO}_{4}^{2-}, \mathrm{NO}_{3}^{-}, \mathrm{Cl}^{-}$, $\mathrm{Br}^{-}$, and $\mathrm{H}_{2} \mathrm{O}$, J. Geophys. Res.-Atmos, 107, ACH 14-1-ACH 14-14, https://doi.org/10.1029/2001JD000451, 2002. 